Supporting information:

\title{
Self-assembly of ionic liquids-stabilized Pt nanoparticles into two-dimensional patterned nanostructures at the air-water interface
}

Hongjun Chen and Shaojun Dong* 


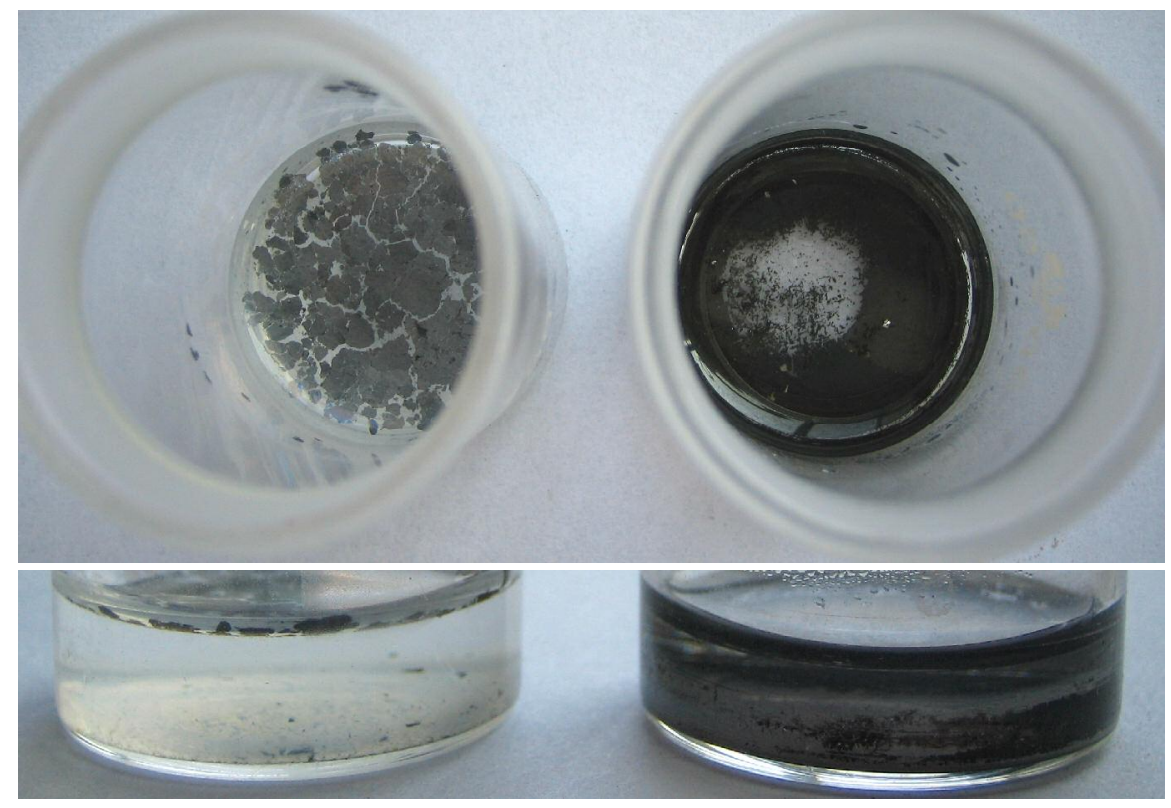

Figure S1. The top and side views of the photographs of the $2 \mathrm{D}$ patterned $\mathrm{Pt}$ nanostructures synthesized by using $200 \mu \mathrm{L}$ [EMIM] $\mathrm{BF}_{4}$ (left) and Pt film produced without the addition of [EMIM] $\mathrm{BF}_{4}$ (right). 